\title{
Experiential collaborations from garment to costume: Play and the thing as design outcome
}

\author{
Martha Glazzard, Sarah Kettley, Tessa Marie Acti and Karen \\ Harrigan
}

\begin{abstract}
Nottingham Trent University (NTU) textile, fashion and interaction practitioners were invited to collaborate with a Danish dance group to contribute a collection of costumes for performances concerned with emotion and the senses, with the ultimate aim of understanding the qualities of audience engagement with dance. This paper discusses the designers' use of play as a methodology, and its relationship to the philosophical notion of the thing, or how artefacts are brought into being. This provides a framework for the deliberate attempt to preserve a level of ambiguity in the outcome of the design process, such that the creative engagement of other stakeholders is explicitly supported. Epistemological and methodological developments have been the result of a number of differences: between the practices and experiences of the design collaborators; between the conceptualisation of costume as static and a need for something new, yet relevant to the themes of emotion; and between the designers' intentions and expectations of how a garment might be used, and the dancers' response to the garments. Outcomes are discussed as moments in a complex and ongoing process, when meanings temporarily coalesce, only to be opened up again. Such a conceptualisation of design has major implications for how we think about methodology, evaluation, material and expertise.
\end{abstract}

\section{Introduction: Sensing Dance, the costume team, and project constraints}

In 2012 we, as textile, fashion and interaction design practitioners at Nottingham Trent University (NTU) (United Kingdom), were invited to collaborate with the Ingrid Kristensen Ballet Company (Denmark) as part of an existing research project, Sensing Dance. This series of dance experiments was funded by the Danish Arts Council, the Region of Southern Denmark and the Municipality of Odense as well a number of smaller sponsorships, and ran from 2010 to 2013. Kristensen's approach allowed for freedom in the evolution of the final outcomes, but put emphasis on the interdisciplinary connections made between the researchers, collaborators, dancers, audience and objects. The project aimed to test different modes of interdisciplinary creative production for increased audience engagement through all the senses, and included collaborations with neuroscientists, branding specialists working with scent, a phenomenological philosopher, interaction designers working with the concept of serious play, 
a sculptor, and new media production. The company's approaches included large-scale installation works, gift-giving, invitations to the audience to take part in familiar dances, the use of warm-up exercises, site specific performances in the urban landscape, and laboratory-based enquiry with professional dancers. Before our involvement, a number of public performances and events had already taken place (Kristensen 2013). This paper presents an analysis of the collaborative, practice-based research that took place between us and the dance company in the creation of costumes for a dance piece to mark the end of the project.

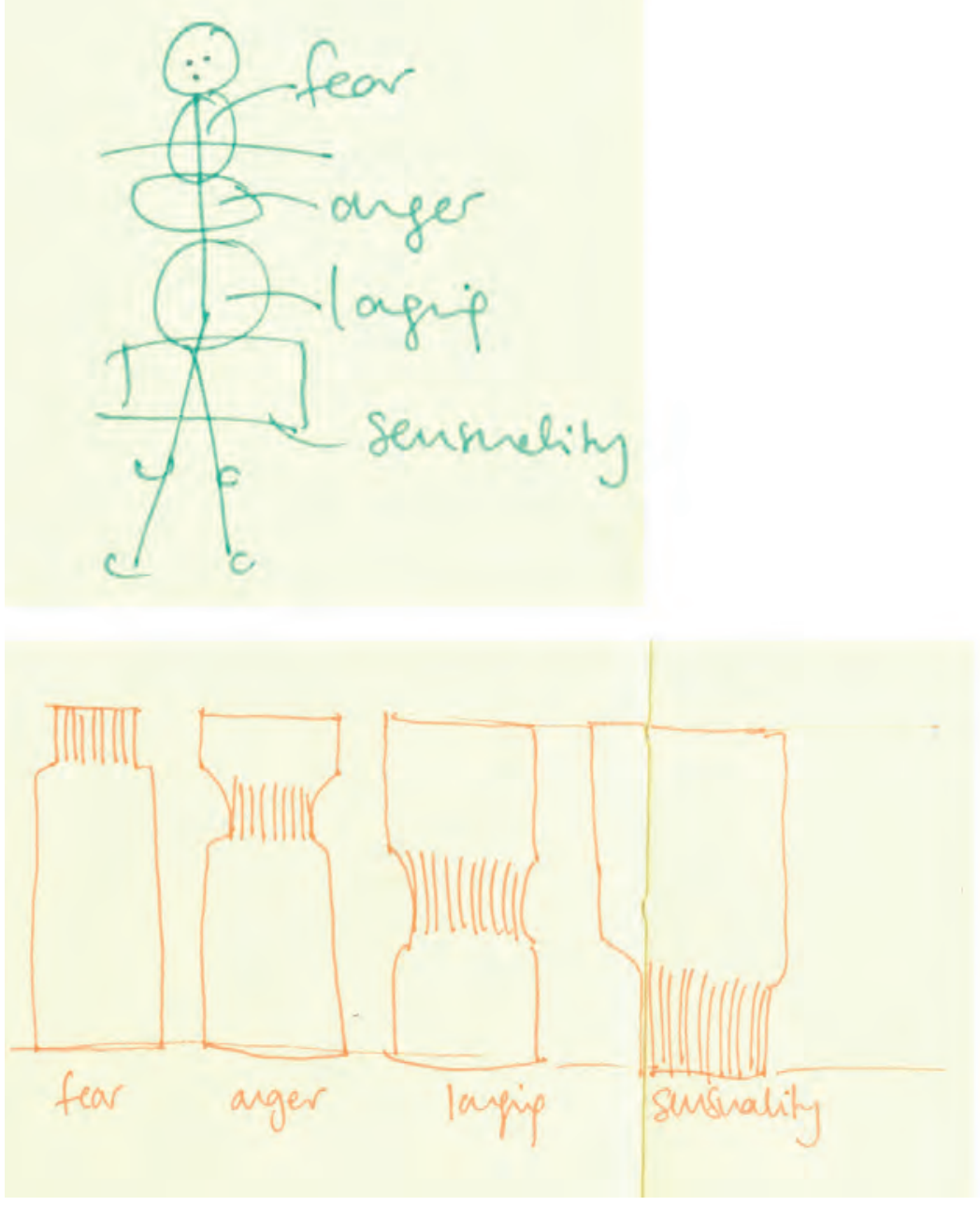

Figure 1. Notes from meetings: mapping emotions to the body, 2012, sketches on paper

Photo: Sarah Kettley, courtesy of the artist

The framework for this final performance was provided by Kristensen's conceptualisation of emotions as having a physical relationship with certain parts 
of the body (Figure 1); the role of the design team was to develop a collection of costumes for the shift from longing to anger, which we were invited to explore through the garments' relationship to the stomach and the throat respectively. These design outcomes had to support in some way the understanding of audience engagement with dance performance and, if possible, increase that engagement. A significant consideration in scoping the project was the time constraint, which precluded the development of computationally interactive garments; however, we believed that fundamental questions about interaction and engagement could still be asked without recourse to 'smart' systems and materials, and that any outcomes would not only support future collaboration with the dance company, but might also contribute to design research. The research aim was to reflexively analyse practice and design outputs through the lens of open design for human engagement.

The costume team at NTU comprised (in alphabetical order): Tessa Marie Acti, embroiderer; Martha Glazzard, knit expert; Karen Harrigan, pattern cutter; and Sarah Kettley, concept and project lead. We were also joined in the early 'play days' by Fiona Hamblin, a jeweller working in mixed media and found objects. Later sections of the paper give details of the exploratory play days, and particular attention is paid throughout to the interplay between different and familiar aspects of practice. Kristensen is also referred to throughout the paper, as the creative director of the Ingrid Kristensen Ballet Company.

\section{Open design and thingliness}

This section describes how 'open design' informed our work, while the next discusses this in relation to definitions of 'thingliness'. During the project, the NTU team had a meta-level goal of continuing our theoretical investigations of open design for user engagement and creativity, an interest since coming together to work with novel stretch sensors in 2008. This view shares characteristics, but is not completely synonymous, with the emerging concept of 'open design' to be found within the discipline of product design, where it has come to stand for a user-led innovation process enabled by shared ownership (without dependency on legal design protection, for example) (Billing \& Cordingley 2011). In the practice-led work of the team with stretch sensing on the body, and in Kettley's earlier work in digital jewellery, openness had been explored through the removal of technological features, ambiguity in the representation of information, minimally predefined functionality, and the emergence of practice as an aspect of craft (Kettley et al. 2010; Kettley 2012; Kettley 2013). In this way these previous projects have attempted to support user meaningmaking and creativity, through opening up instead of closing down definitions of use, experience and ownership, and this is what we conceptualised as 'open design'. The Sensing Dance project represents a new stage in the evolution of our collective practice, which includes smart materials and systems, but which 
is not defined by them. The concept of thingliness now allows us to reflect on the evolution of this conceptualisation of open design, as well as providing a tool for tracing the changing status of our design outputs.

\section{Differences/things}

In Bruno Latour's actor-network theory (ANT), the word 'thing' (after the German 'Ding') is conceptualised as having two meanings - it is at once an issue or controversy, and the gathering of actors that comes together around an issue (Latour 2005). These actors include not only individuals, but also ideas (in this case, for example, of what a costume is), and infrastructures (research funding and institutions), technologies, skills and practices. While this conceptualisation is taken from ANT we have also been influenced by Christiano Storni's use of it to account for the emergence of new practices and forms in the design of a range of jewellery (2012). At the same time, the designed artefact oscillates between states of openness or thingliness, and definition, or object-hood. Storni traces this to some extent as the design concept for a finger ring evolves in his case study of collaboration between two jewellers, but his paper does not extend to the life of the artefact beyond this process; that is, as it is presented to the jewellery fair, selected by retailers, or purchased and worn by customers - he points the reader to the socio-technical literature for this. We feel that our design efforts will benefit from a conceptualisation of our outputs as being more thing than object, and from being confident in our ability to design for, trace, and evaluate such oscillations.

As Storni points out, a thing comes into being because of difference; aspects of an artefact cause actors to come together to work through possible meanings (2012: 92-94). We encountered many such sites of contention or 'thingliness' as we developed the costumes and in the following sections we discuss the three that we see as most influential throughout the project. These were:

1. differences between the practices and experiences (methodologies) of the design collaborators

2. differences between the conceptualisation of costume as static and a need for something new, yet relevant to the themes of emotion

3. differences between the designers' intentions and expectations of how a garment might be used, and the response to the garments from the dancers.

\section{Difference: Practices and experiences}

The first site of difference was afforded by the range of disciplines brought into play by the individual practitioners in the team. Based on previous experience, this was framed positively as an integral part of the interdisciplinary approach, and managed through the use of intense shared workshops or play days. In these, initial investigation into form and process took place with all design 
collaborators sharing techniques and materials from previous work to develop the ideas of 'longing' and its being represented through the stomach. The themes of stretch, gaps, and crossing those gaps were brought forward from previous group work (Glazzard \& Kettley 2010; Kettley et al. 2010: 253) and combined with Kristensen's suggestions on how 'longing' might be embodied (Figure 1).

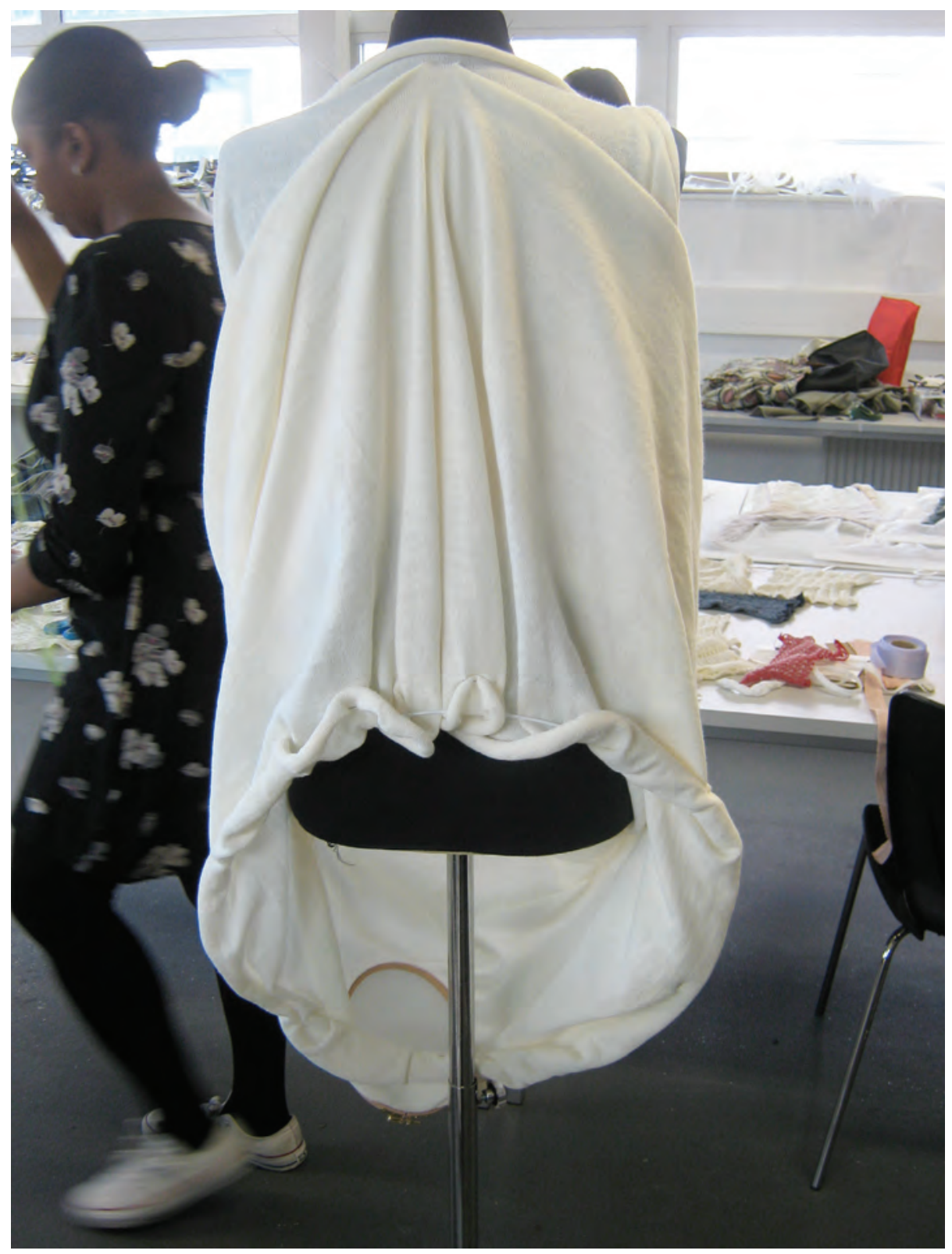

Figure 2. Experimentation with knitted tubes on mannequins, 2012 


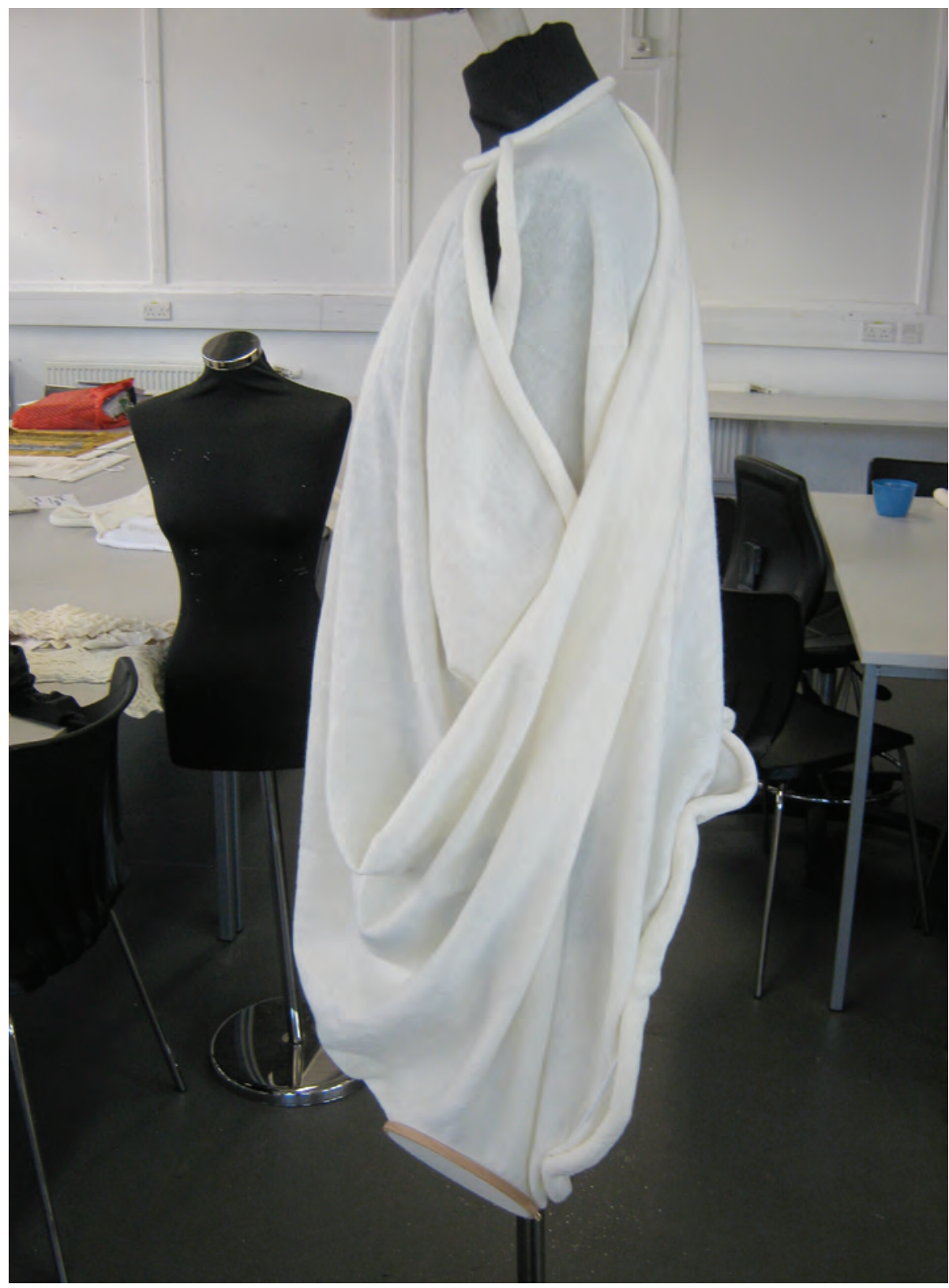

Figure 3. Draping fabric on the mannequin to define shape, 2012

Photo: Martha Glazzard, courtesy of the artist

During the play day, individuals' perspectives and ideas were put forward in an open forum. Practitioners brought fabric, yarns, props, pins and cameras, amongst other objects. Individuals, pairs or small groups conducted their own experiments. Some of these experiments involved draping fabric on stands (as 
shown in Figures 2 \& 3), considering form and techniques, and some were material exploration with movement. Human gesture and interaction formed a part of the design process. We assumed there would be, and tried to allow for, an element of stretch and force between dancers or between each dancer and his or her costume.

Tubes of knitted fabric (knitted on an industrial, circular knitting machine) were used to plan the basis of each garment. The elements brought from previous practices and interests were experimented with to see how they might attach and interact with a fabric ground (the tubular fabric). Because of each practitioner's extensive experience in handling and learning the properties, behaviour and possibilities of fabrics (Aldrich 2007: 5), it was possible to be unstructured in the design process. This methodology permits changes and developments in reaction to external and self-imposed limitations that are introduced during the project.

\subsection{Individual practices and observations}

Though different practices were involved in the designing and making of the costumes, each practitioner was considered equal with their individual expertise bringing specialist knowledge to the project. Both Glazzard and Harrigan approached the design task from a pragmatic perspective and included the aspects of time, material and machinery limitations into the design process (Eckert 1999: 33). From experience of working on collaborative garment design tasks where the end user is remote and unseen (in this case unknown), they adopted an approach that fed inspiration from the materials and techniques available to them both physically and through their making experience. Exploring the dichotomous relationship between material play and mechanical exploration, Acti's methodology questions the value of mass-produced embroidery and, in this collaboration, she explored the artistic application of long thread structures (Figure 4). These structures were used to attach knitted tube garment forms together to create interactive costume pieces. The same slits were used to provide openings for wearers, and a hoop form to match one of the other garments was used to create cohesion between the outfits.

Glazzard and Harrigan both have garment-making experience and initially addressed the design task as a garment-making project utilising their experiential knowledge. Issues to be considered included asking - Who is the wearer? and What do we know about their size and their requirements from the costumes? In reality we knew very little about the individual dancers' sizes or heights, or even the exact number of dancers. Because of these unknown variables the garments were designed free-sized, allowing stretch and movement, while retaining strength against the dancers' movements. These design decisions used experiential observations from knowledge of knitted fabric structures and garment production. Knitted fabric was specifically used to provide stretch and movement for the dancers and large, seamless tubes could be produced to create large tubes without traditional weak points caused by seams. In order to make the tubes into garments, holes were added to provide loose and adaptable head/arm/leg openings. Keeping these holes away from the centre 
of the tubes provides fuller shapes to benefit a performance outcome. Draping and modelling on mannequins and stands was used as a key method (AmadenCrawford 1989; Joseph-Armstrong 2013) to determine silhouette, length and practical make-up decisions. This experimental method allowed for a 'fabricled' approach (Glazzard \& Breedon 2012: 105). These stages were not acted out in a linear order, but were often considered concurrently or in alternating, circular and iterative manners, with experiential observations and methods feeding into the task-specific questions and considerations.

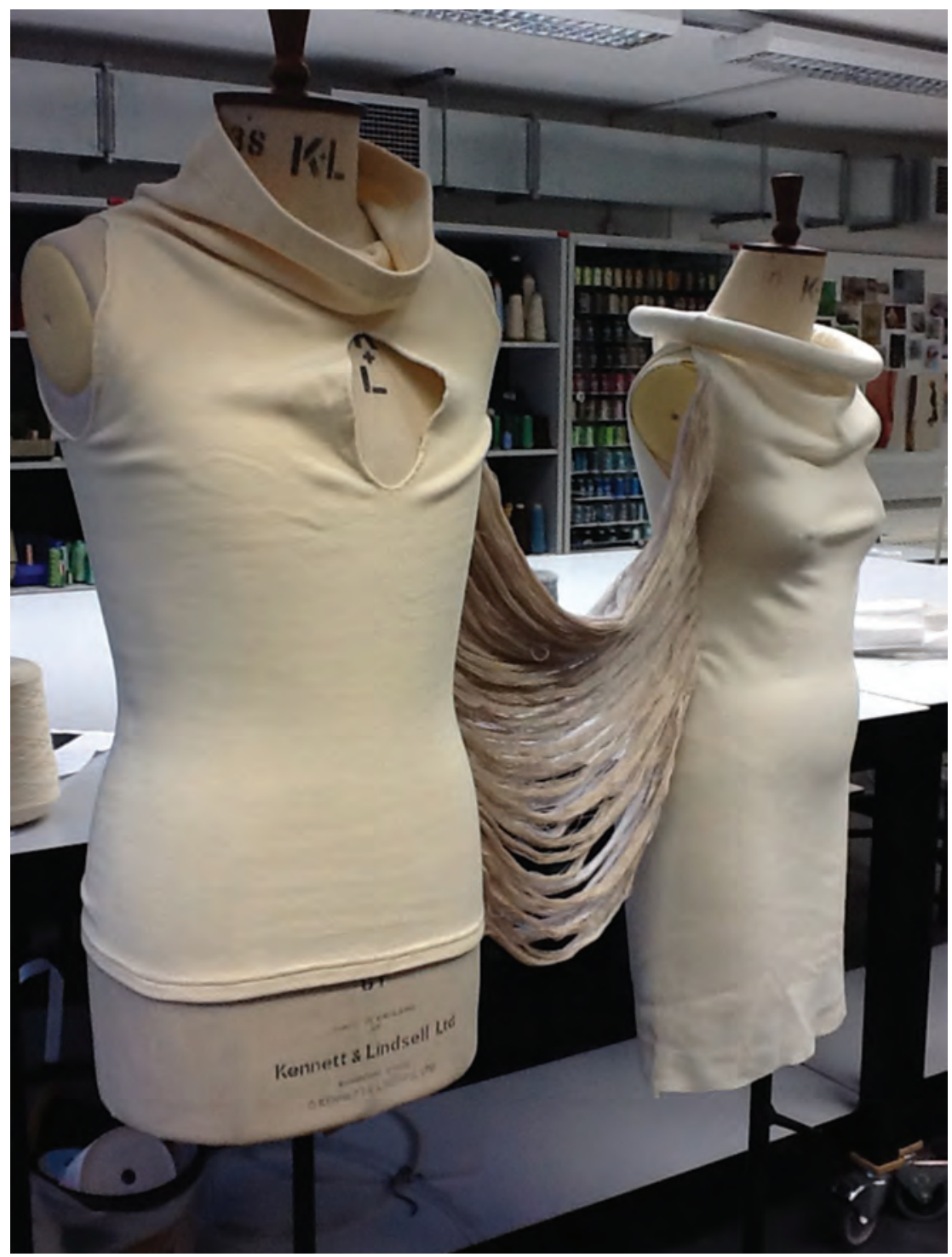

Figure 4. Long thread embroidery and knitted tubes during development, 2012, mixed fibres

Photo: Sarah Kettley, courtesy of the artist 
The fabric dictated a large part of the method. In fashion and knitwear practices, there is an established history of reacting to the fabric (Aldrich 2007: 5). By choosing to work this way, the designers impose limitations on themselves, which is often beneficial in the design process. Various constraints imposed by the original brief, the end users, the play day decisions and the group-working method had already been imposed, but this still left a huge number of creative possibilities for the designers (Francis \& Sparkes 2011: 59). Because of the practice of Harrigan in pattern cutting and Glazzard in knitted textiles, the process of working in a fabric-led manner around the properties of the knitted tubes was a logical step. In this method, the material dictated the processes. Traditional knitwear sewing machinery (such as a seam-cover) was used and, where possible, the natural tendency of the fabric to roll was used as a design feature, rather than being hidden. In the slits for example, the fabric was rolled back and hand-finished for security and strength. This would withstand rigorous use by the dancers by being firmly secured at weak areas, but stretch would not be constrained as it would when using a machined seam.

Because of experience in building collections of garments for fashion or knitwear contexts, Glazzard and Harrigan employed many methods known to clothing designers in the assembly of fashion collections. Some of these considerations, such as using a limited colour palette, limited fabric types, and producing garments for multiple bodies/wearers, were developed in communications with Acti and Kettley to create the final garments. The collection required similarity across garments, but with differences in features. Each garment had groupings with another garment to provide the look of a clothing collection; that is, a combination of some feature, colour, fabric or shape that created a visual tie-in with another garment in the collection (Frings 1999: 179). These considerations were developed to fit the given brief and the extra elements were devised by group discussions and the play days.

This process allowed the designers to be confident in their experience of making garments, while the outcome was to be a costume. In this way the design process was allowed to remain similar to the normal process for these practitioners. Individuals' confidence grew when more autonomy was established for the garments to be developed within existing design knowledge frameworks. The transformation (or thinging) of the garments was external to this design process. Glazzard and Harrigan's key concerns as designer/makers were the professional and robust finish, strength and suitability of the garments, elements of closure and definition, criteria set by the design brief, but also imposed by disciplinary expertise.

\section{Difference: Costume as static, new, emotive}

The second major site of difference or thingliness in the process was the conceptualisation of what a costume is or should be. Design itself has been described as always being concerned with redesign, of being largely concerned with the known object rather than the unknown thing (Latour 2008); in previous 
work we have found that different craft and textile related disciplines work with levels of object-hood and openness in different ways and in this project, these differences were tested further by the term costume, and our conceptualisations of what costumes are, should be, or might be. Generally speaking, we were aware that costumes are normally organised around a given narrative or known character in a specific cultural context; in dance, functional considerations are generally concerned with ease of movement dependent on a given genre of dance. Given the brief, however, we did not expect to make costumes that used such aesthetic codes, but sought to use practical skills to work towards an emotional outcome, developing an abstract semiotics of emotions in relation to movement (Sandhu 2008: 7). A far more comprehensive approach to a literature review in this area is still needed to further underpin our investigations, but in the meantime, we have been aware of work that puts the body at the centre of an indeterminate design process (Wilde \& Anderson 2009), that highlights the networks of actors involved in the creation of meanings through garment forms which invite movement (Bugg 2008; Candy 2007), and of the shift towards the performative in fashion theory (cf. Entwistle \& Wilson 2001). Therefore it can be seen that while the term 'costume' normatively embodies closure and a predetermined system of signs, the team were open to experimentation with a view to the design outcome remaining open and engaging. Just how the costumes engaged the dancers became apparent when images were sent to the team showing the dancers opening the packages of costumes for the first time (Figures 5 and 6).

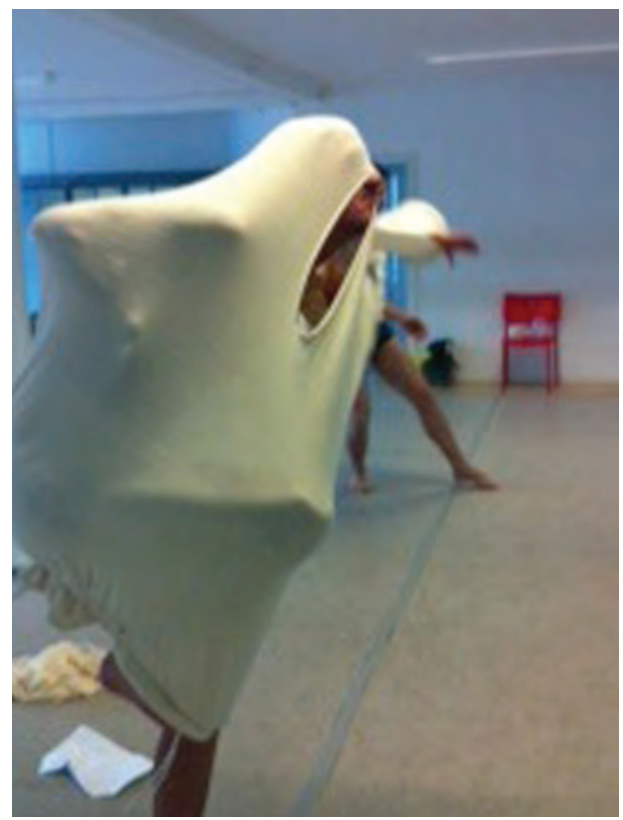

Figure 5. Dancers' first reactions to the costumes, 2012

Photo: Ingrid Kristensen, courtesy of the artist 


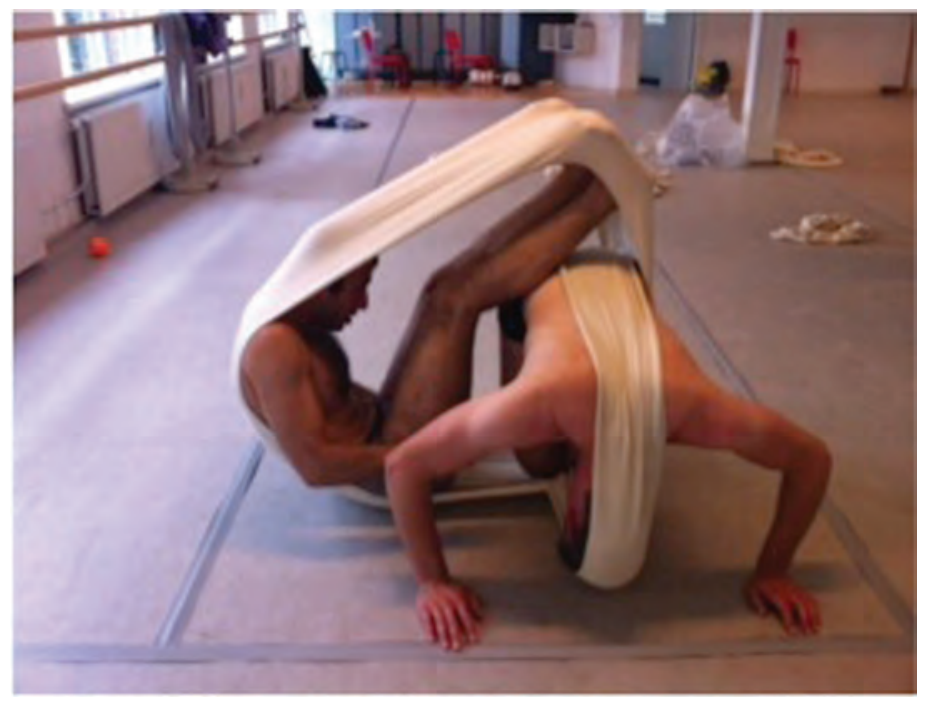

Figure 6. Dancer's initial reactions to the costumes, 2012

Photo: Ingrid Kristensen, courtesy of the artist

\section{Difference: Intentions, expectations and responses}

The third and most surprising site of thingliness only became apparent in the reaction of the dancers to the garments. This difference was crucial in transforming the garments into costumes.

From the approaches of the designers to the documentation of the design process and final outcomes it was clear that the ideas were framed within the context of how they would function as conventional garments. The language used was indicative of such thoughts - garments were referred to as 'trousers' and 'tops' and the loops as 'scarves' or 'accessories'. Openings were considered for legs, arms, and heads accordingly. There was a recognition that the end use of the garments probably would not adhere to these conventions, but for the process it was necessary for effective communication and to observe familiar conventions for the designers in using a shared reference point in language of which each practitioner could share an understanding (Eckert \& Stacey 2000: 524). As such, a set of guidelines was prepared by the designers to help the dancers approach the garment forms for the first time, including images of the forms being held or manipulated on stands (Figure 7 shows a proposed way of wearing the garment). 


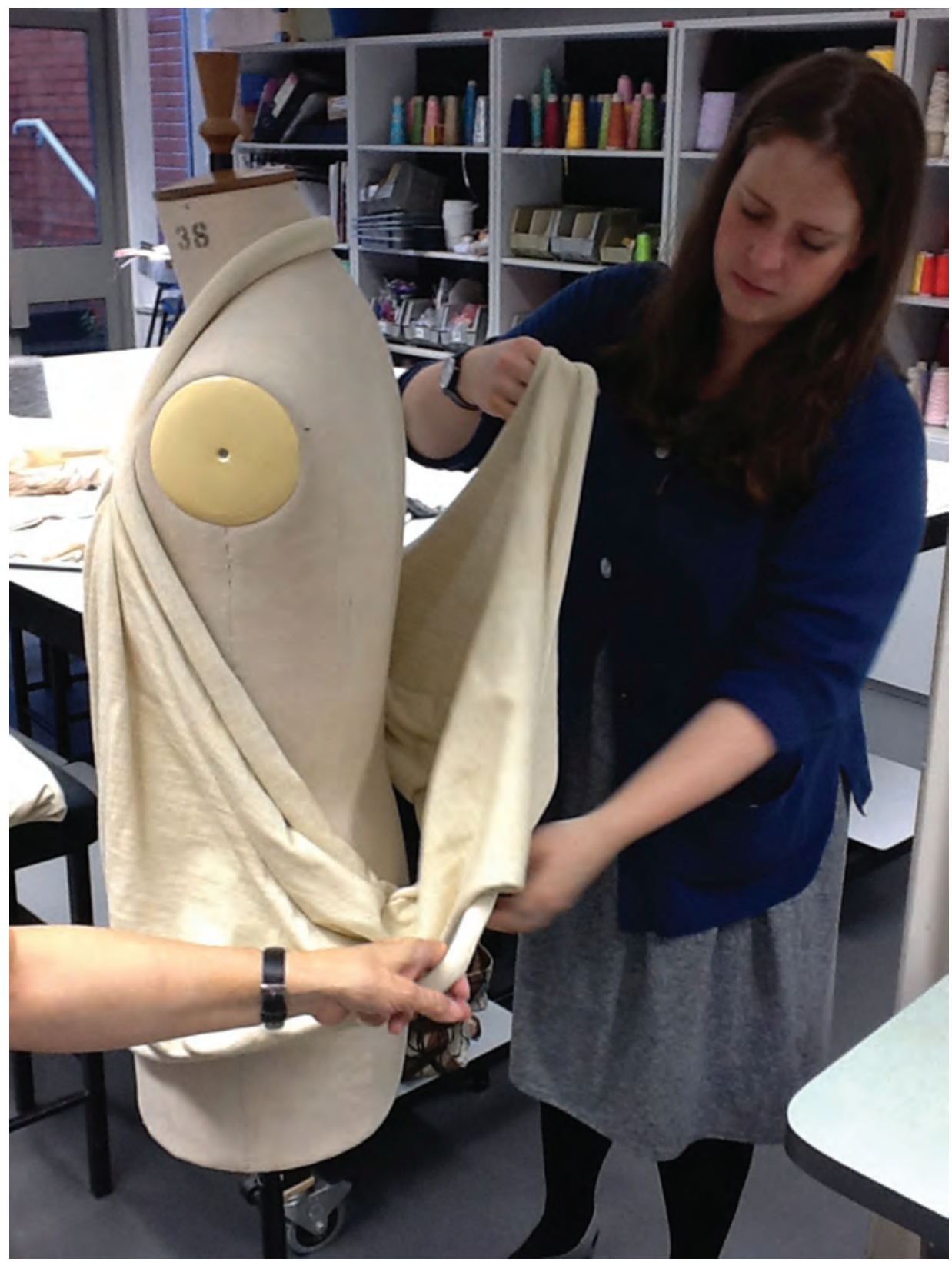

Figure 7. Designers' ideas of how dancers would dress the costumes

Photo: Sarah Kettley, courtesy of the artist

An excellent example of the discrepancy between the designer and the user in this case is the use of the knitted 'loops' (Figure 8). The loops were cut from the remaining circular fabric and demonstrated large amounts of stretch in the play day session. For this reason, more were made and sent with the garments 
as accessories or props for interaction. On receipt of the loops, the dancers wound whole bodies into the loops, not as accessory, prop or garment, but as costume (Figure 9).

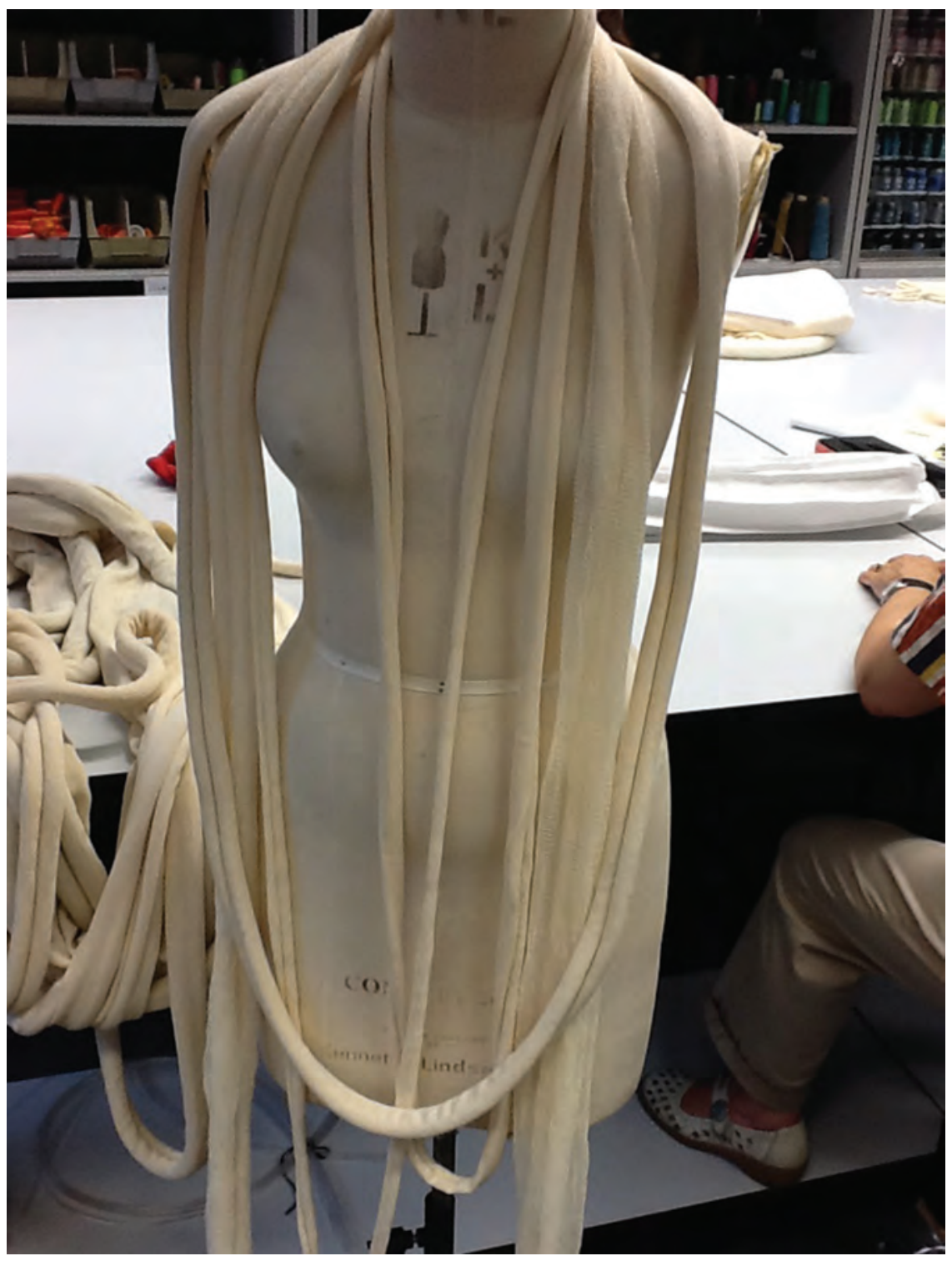

Figure 8. Knitted loops during development, 2012, mixed fibres

Photo: Sarah Kettley, courtesy of the artist 


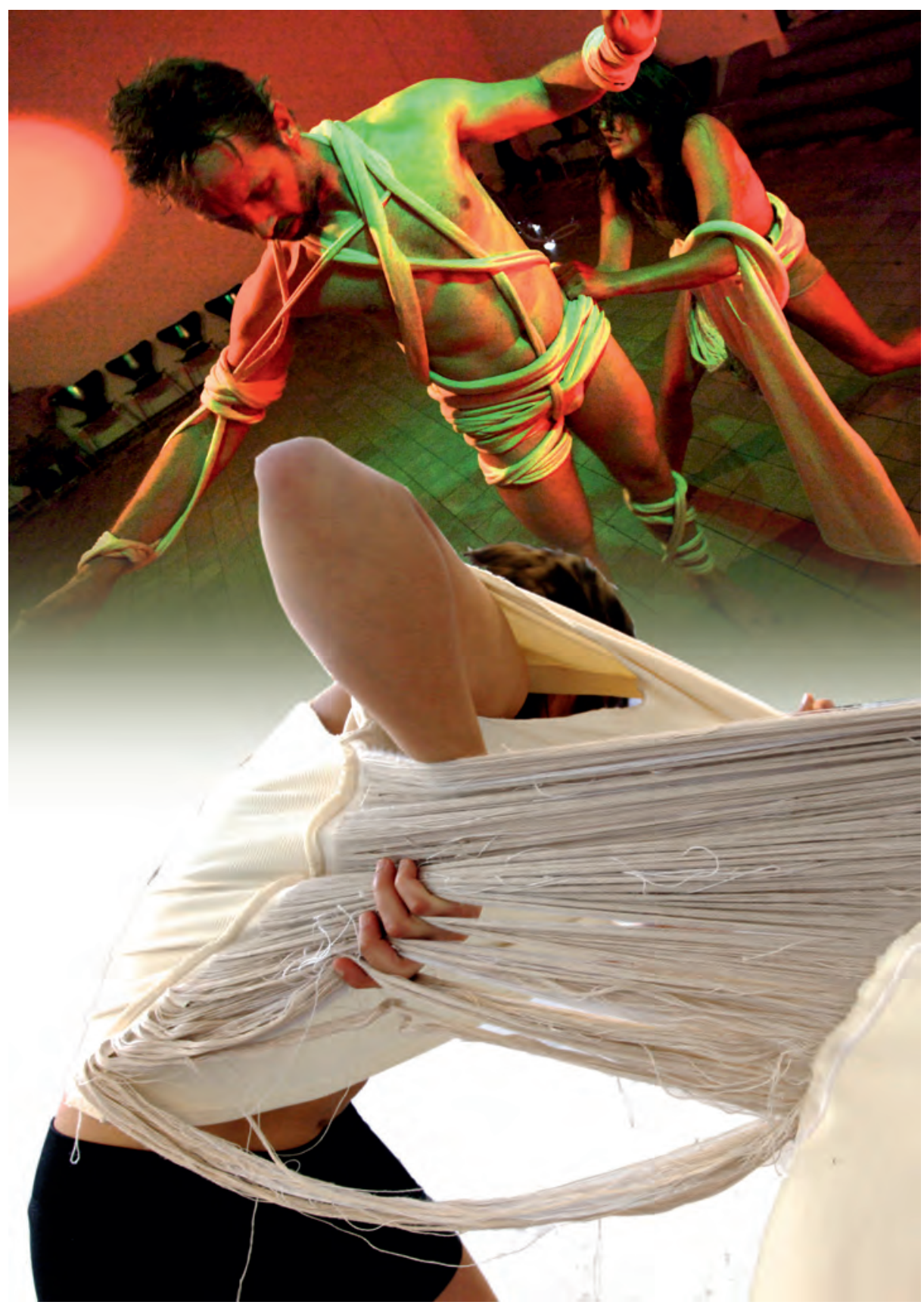

Figure 9. Knitted loops during performance, 2012, photograph of performance

Photo: Anders Vejen Andersen, courtesy of Anders Vejen Andersen and Ingrid Kristensen \& Co

Had the development of the costumes taken place using discussion and physical input from the dancers, the final costumes would arguably have been 
different, with a different set of actors in place (Storni 2012). The addition of further agendas may have clouded the simple creativity of the designers and prevented self-directed confidence in each individual's skill and input. Had we known that all the dancers might have climbed into one garment, we would have altered the size or shape, which would, ultimately, not have provided the same effect during the performance. In fact, in rehearsal and performance with the costumes, dancers approached them from their own perspectives and transformed the fashion and garment-based ideas into performance, space, structure and body extensions. This highlights the importance of difference (the necessary condition of thingliness) for working between the production of a garment through one set of experiential knowledge and the enaction of a costume through another set of experiential knowledge.

\section{Conclusions, new audiences and further work}

We borrow again from Storni here to describe the creative engagement that undecideable design outputs, such as the costumes, are intended to invite. He used the term tendency to discuss the creative forces brought to bear on artefacts, showing that at any moment they may be subject to other actors' thinging (opening and multiplying) or objectifying (fixing and stabilising) tendencies (2012: 109-13). For the purpose of our work we draw on this to identify user or audience engagement as the willingness to actively engage in thinging tendencies, which allows us to approach some kind of meaningful evaluation of the work.

In discussion the dancers revealed that they found a freedom in having bespoke outfits, rather than modified garments, with which to experiment. They were not limited by the constraints of the designers' preconceptions of either the garment forms, or of the choreographic process, images of which revealed the costumes playing a significant role in the development of the performance. Images of the group trying on the pieces for the first time show packaging lying discarded around the studio floor as if on Christmas morning - there is a palpable air of excitement (Figures 5, 6 \& 12). Feedback from the dancers after the Sensing Dance performances spoke of their unusual chance to develop story and character in response to the garments, and the way this sense of agency carried into performance to be reciprocated by the audience; in their terms, they found the audience to be more receptive to their 'invitations to connect' through movement and expression. Instead of 'smart' textiles and computational wearables engaging audiences through technology, it seemed that the open nature, or thingliness, of the costumes had a powerful and complex effect on the relationship between performer and audience. 


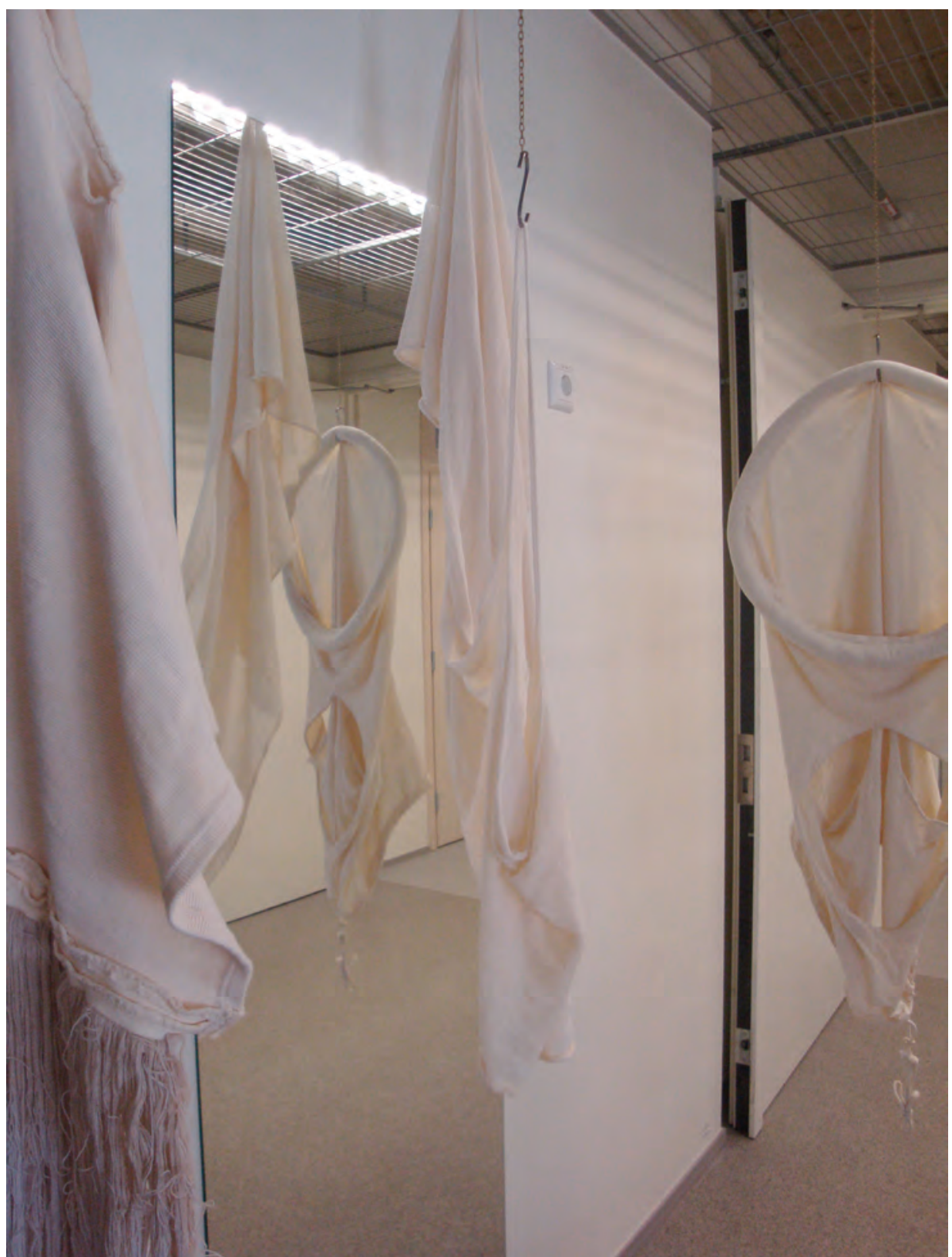

Figure 10. Installation of Sensing Dance costumes at Fragile?

Photo: Sarah Kettley, courtesy of the artist 


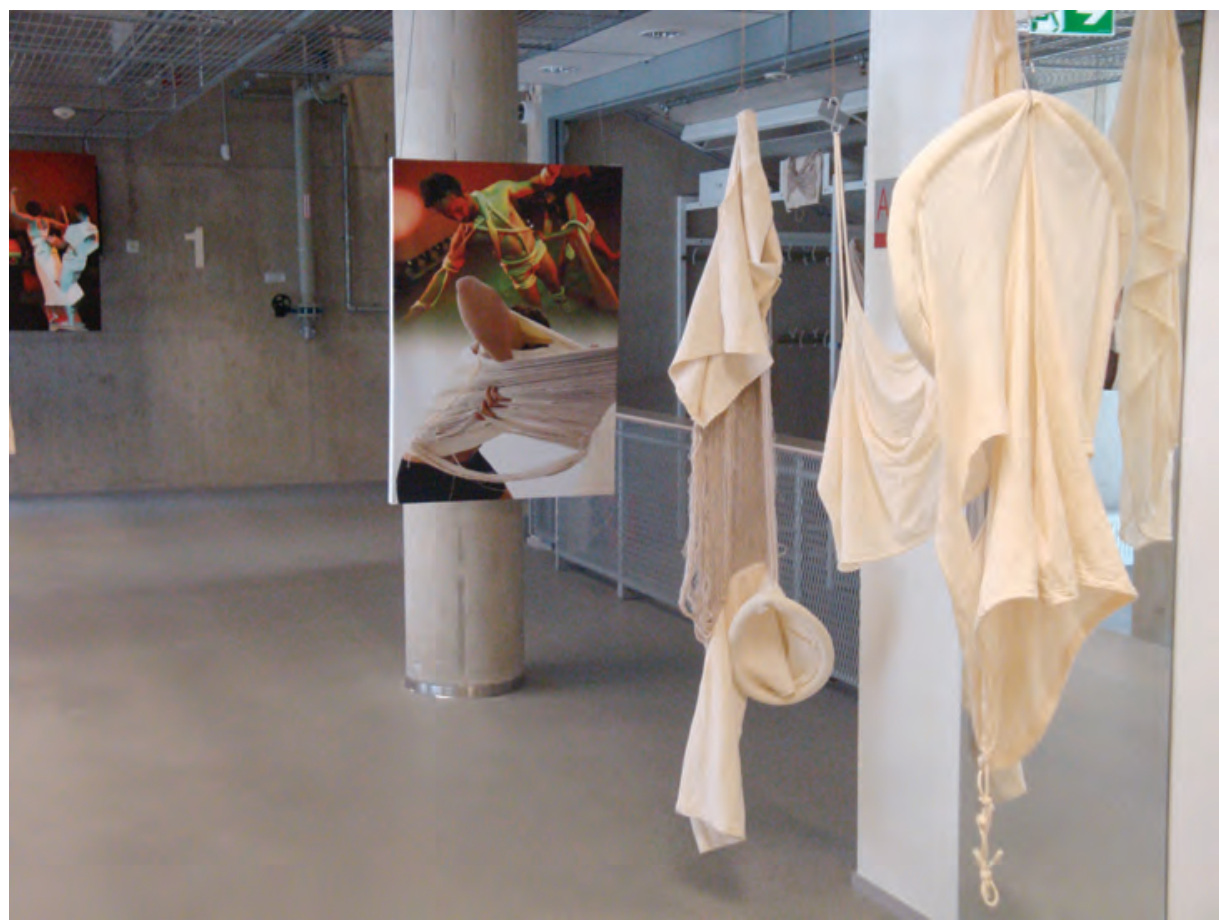

Figure 11. Installation of Sensing Dance costumes at Fragile?

Photo: Sarah Kettley, courtesy of the artist

Featured Photos: Anders Vejen Andersen, courtesy of Anders Vejen Andersen and Ingrid Kristensen.

An invitation to show the costumes and images of Sensing Dance at another event has provided further reflection on the costumes as things. The Fragile? Symposium marked the end of a European project on dance and sightimpaired performers, and included the premieres of three dance pieces, invited talks, a site-specific performance, and a series of demo workshops (Fragile? 2013). In this case the costumes were not on a body, but were hung inanimate from hooks attached to a ceiling grid in a corridor of the Astra building of Tallinn University (Figures $10 \& 11$ ). An integral part of the exhibit was three large full-colour photographic montages of the costumes in performance with Kristensen's dancers. As a whole, the arrangement of textiles and images aimed to invite the whole body of the visitor into the space, and to involve them physically and emotionally.

Reactions to the work were visceral: visitors reported that it was disconcerting, even 'creepy', and that the costumes reminded them of shed skins; the images of dancers wound tightly in the loops, straining against the fabric, made them anxious, while the hooks used to display the work had the unintended effect of reminding them of flesh and flayed animals. The work had not been designed for the Fragile? choreographic processes, but was invited as an example of an approach to design which puts the agency of the individual at the centre of the 
process (Kettley 2013). While it is interesting to observe that the visitors had similar emotional reactions to the costumes as the dance audiences, in fact, the criterion for success for the designs is their openness to new interpretation; that is, their ability to segue between object and thing.

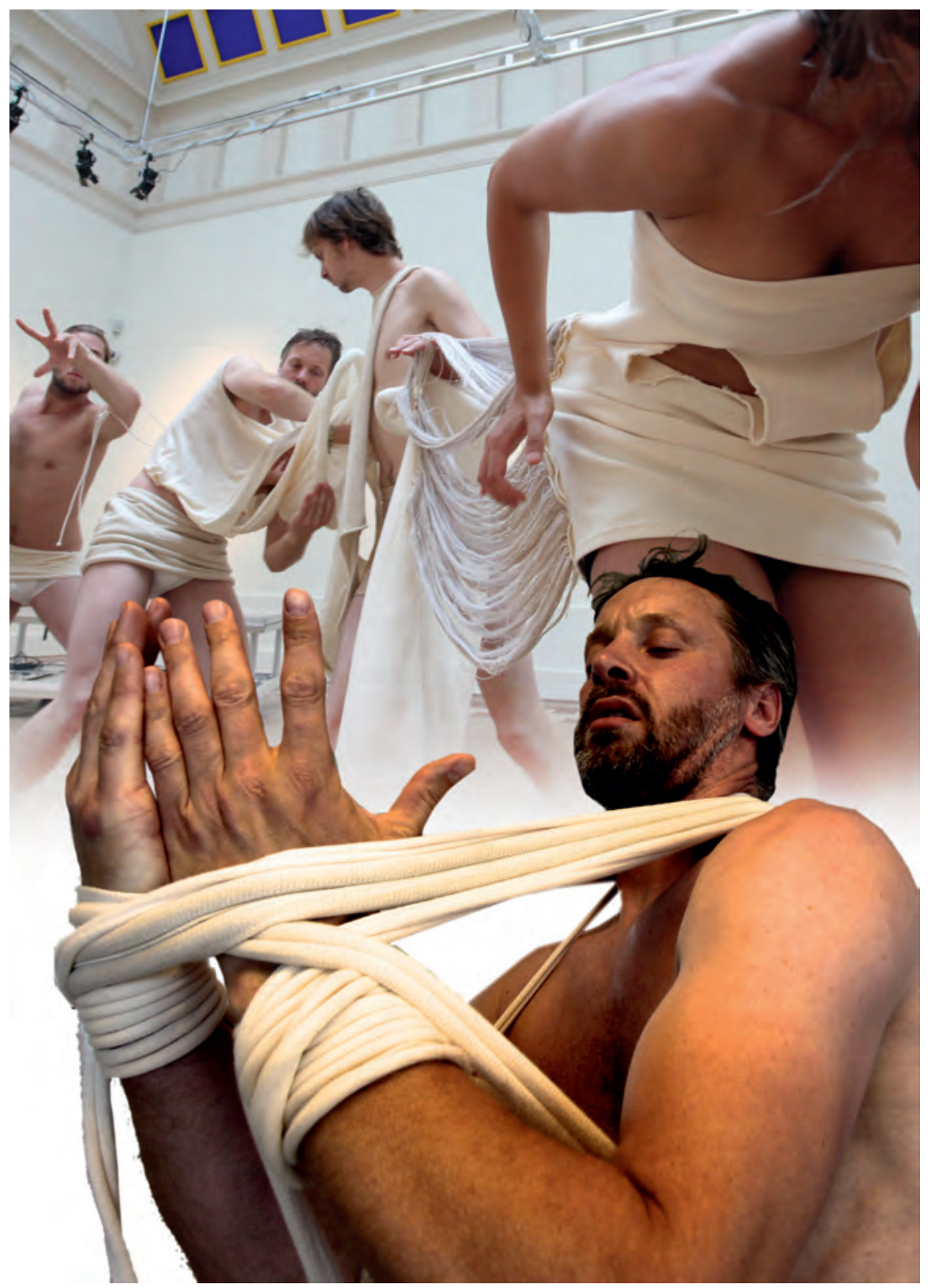

Figure 12. First encounters between dancers and costumes, 2012, photograph of 
rehearsals

Photo: Anders Vejen Andersen, courtesy of Anders Vejen Andersen and Ingrid Kristensen

From this work, we suggest that supporting the performer's engagement with their materials (direction, choreography, narrative, scenography, costume) through open design is an important strategy for audience engagement. We now plan to take forward our methodological learning from this practice-based reflection in the form of a large five-year dance research project, which will introduce new 'smart' technological actors to the shared practice. We hope that our work will contribute to debates in interaction design practice around audience engagement, through demonstrating the potential power of design outcomes as open things.

Martha Glazzard is a practitioner and researcher in textile design, specialising in knitwear and knitted structures. Her work assesses the relationship between functionality and the methods by which it is produced. She is interested in how material and structure dictate form and how experiential knowledge can shape decision-making processes.

Dr Sarah Kettley is course leader for MA Product Design at Nottingham Trent University, with research interests in design for wellbeing, craft theory and interaction design. She is a member of the international Arcintex research network for Architecture, Interaction Design and Textiles, and an elected council member of the Design Research Society.

Tessa Marie Acti is an artist, research assistant and technician exploring digital embroidery. Her practice is based on challenging traditional perceptions of mass production digital embroidery.

Karen Harrigan is a senior lecturer in Fashion Design with specialist knowledge of pattern cutting. She is interested in the generation of innovative shapes and how these are applied to the body. She is inspired by other creative disciplines and how these can be further developed into 3D forms. She specialises in 2D-3D translation techniques, employing innovative approaches to both flat and draping methods.

\section{References}

Aldrich, W. 2007, Fabric, Form and Flat Pattern Cutting, 2nd edn, Oxford: Blackwell.

Amaden-Crawford, C. 1989, The Art of Fashion Draping, New York: Fairchild Publications.

Billing, J. \& Cordingley, T. 2011, 'Open design: Driving product design innovation through new collaborative working practices and professional models, Design Principles and Practices: An International Journal, vol. 5, no. 5, pp. 299-312. 
Bugg, J. 2008, 'Concept, context and communication: Interrelationship: designer, viewer, wearer' in The Body: Connections with Fashion, proceedings of the 10th Annual Conference of the International Foundation of Fashion Technology Institutes (IFFTI), Melbourne, Australia.

Candy, F.J. 2007, "Come on momma, let's see the drummer": Movement-based interaction and the performance of personal style', Personal and Ubiquitous Computing, vol. 11, no. 8, pp. 647-55.

Downes, T. et al. 2011, 'Digital embroidery: Intuitive process based on tacit knowledge or dichotomy between computer screen and material reality?, conference paper, Textile in Research Practice Symposium, Loughborough University, 16 November.

Eckert, C. 1999, 'Managing effective communication in knitwear design', The Design Journal, vol. 2, no. 3, pp. 29-42.

Eckert, C. \& Stacey, M. 2000, 'Sources of inspiration a language of design', Design Studies, vol. 21, no. 5, pp. 523-38.

Entwistle, J. \& Wilson, E. (eds) 2001, Body Dressing, Berg.

Fragile? 2013, Symposium: Dance, arts \& visual impairment, viewed 12 July 2013, http://fragiledance.com/eng/page/symposium/

Francis, N. \& Sparkes, B. 2011, 'Knitted textile design', in A. Briggs-Goode \& K. Townsend (eds), Textile Design: Principles, Advances and Applications, Oxford: Woodhead, pp. 55-85.

Frings, G.S. 1999, Fashion: From Concept to Consumer, 6th edn, Upper Saddle River, NJ: Prentice Hall.

Glazzard, M. \& Breedon, P, 2012. 'Designing a knit methodology for technical textiles', in Smart Design: First International Conference Proceedings, pp. 103-08.

Glazzard, M. \& Kettley, S. 2010, 'Knitted stretch sensors for sound output', in Proceedings of the Fourth International Conference on Tangible, Embedded, and Embodied Interaction (TEI '10). New York: ACM, pp. 391-92.

Joseph-Armstrong, H. 2013, Draping for Apparel Design, 3rd edn, New York: Fairchild Books.

Kettley, S. 2012, 'Interrogating hyperfunctionality', in P. Breedon (ed.), Smart Design, London: Springer Verlag.

- - 2013, 'How do costumes engage dancers and audience?' in I. Kristensen (ed.), Discover the Movements: Added Value through Dance, Odense: Ingrid Kristensen \& Co, pp. 24-27. 
Kettley, S., et al. 2010, 'Fit for purpose? Pattern cutting and seams in wearables development', Digital Creativity, vol. 21, no. 4, pp. 247-56.

Kristensen, I. (ed.) 2013, Discover the Movements: Added Value through Dance, Odense: Ingrid Kristensen \& Co.

Latour, B. 2005, Reassembling the Social: An Introduction to Actor Network Theory, Oxford University Press.

- - 2008, 'A cautious Prometheus? A few steps toward a philosophy of design', in Networks of Design: Proceedings of the 2008 Annual International Conference of the Design History Society (UK) University College Falmouth, 3-6 September, Boca Raton: Universal Publishers, pp. 2-10.

Renfrew, E. \& Renfrew, C. 2009, Developing a Collection, Lausanne: AVA Academia.

Sandhu, A. 2008, 'Fashion design: Desires and emotions', conference paper, 6th International Conference on Design \& Emotion, The Hong Kong Polytechnic University, 7-9 October 2008.

Storni, C. 2012, 'Unpacking design practices: The notion of thing in the making of artifacts', Science Technology Human Values, vol. 37, no. 1, pp. 88-123.

Wilde, D. \& Anderson, K. 2009, 'Doing things backwards: TheOWL project', OZCHI 2009: Proceedings of The Australasian Computer Human Interaction Conference, New York: ACM, pp. 357-60. 
This text taken from craft + design enquiry issue 6, 2014, Craft.Material. Memory, Edited by Anne Brennan and Patsy Hely, published 2014 by ANU Press, The Australian National University,

Canberra, Australia. 